IZA DP No. 5422

The Long-Run Effects of Mortality Decline in Developing Countries

Ulla Lehmijoki

Tapio Palokangas

January 2011 


\title{
The Long-Run Effects of Mortality Decline in Developing Countries
}

\author{
Ulla Lehmijoki \\ University of Helsinki, \\ HECER and IZA
}

\section{Tapio Palokangas \\ University of Helsinki, HECER and IZA}

\section{Discussion Paper No. 5422 \\ January 2011}

\author{
IZA \\ P.O. Box 7240 \\ 53072 Bonn \\ Germany \\ Phone: +49-228-3894-0 \\ Fax: +49-228-3894-180 \\ E-mail: iza@iza.org
}

\begin{abstract}
Any opinions expressed here are those of the author(s) and not those of IZA. Research published in this series may include views on policy, but the institute itself takes no institutional policy positions.

The Institute for the Study of Labor (IZA) in Bonn is a local and virtual international research center and a place of communication between science, politics and business. IZA is an independent nonprofit organization supported by Deutsche Post Foundation. The center is associated with the University of Bonn and offers a stimulating research environment through its international network, workshops and conferences, data service, project support, research visits and doctoral program. IZA engages in (i) original and internationally competitive research in all fields of labor economics, (ii) development of policy concepts, and (iii) dissemination of research results and concepts to the interested public.
\end{abstract}

IZA Discussion Papers often represent preliminary work and are circulated to encourage discussion. Citation of such a paper should account for its provisional character. A revised version may be available directly from the author. 
IZA Discussion Paper No. 5422

January 2011

\section{ABSTRACT}

\section{The Long-Run Effects of Mortality Decline in Developing Countries}

Since World War II, mortality has declined in the developing world. This paper examines the effects of this mortality decline on demographic and economic growth by a familyoptimization model, in which fertility is endogenous and wealth yields utility through its status. The decline in mortality stimulates investment and generates an income stream which promotes population growth, but the desire of status hampers fertility and prevents capitaldiluting demographic expansion. If status-seeking is strong, then the decline of mortality decreases population growth below its original level.

JEL Classification: $\quad \mathrm{O} 41, \mathrm{~J} 13, \mathrm{J10}, \mathrm{O} 10$

Keywords: mortality, population growth, economic growth

Corresponding author:

Tapio Palokangas

Department of Political and Economic Studies

P.O. Box 17 (Arkadiankatu 7)

Economicum Building

FIN-00014 University of Helsinki

Finland

E-mail: Tapio.Palokangas@helsinki.fi 


\section{Introduction}

Developing countries have in the post-war era faced a decline in premature death: malaria and tuberculosis have diminished, and infant and maternal mortality have approached the standards of the advanced countries. ${ }^{1}$ This decline in mortality has certainly been welfare enhancing, but has it affected the patterns of population growth and capital deepening?

On the one hand, the "Malthusian pessimists" claim that a mortality decline decreases the costs of children (Doepke 2005). This boosts population growth, diluting income per person (Malthus 1798, Young 2005, Acemoglu and Johnson 2007). On the other hand, the "optimists" claim that the increase of longevity stimulates investment in physical and human capital, helping economies to escape the Malthusian trap (Galor and Weil 2000, Blackburn and Cipriani 2002, Ehrlich and Liu 2005, Soares 2005, Albanesi and Olivetti 2010).

Empirical research has not yet solved this dilemma. On the one hand, Zhang and Zhang (2005) show that mortality decline decreases fertility and increases the resources in schooling, thus rising economic growth, and Weil (2007) argues that the elimination of health gaps would decrease the variance in per capita income between countries. On the other hand, Acemoglu and Johnson (2007) show that a fall in mortality raises population more than capital, thus decreasing per capita GDP.

In the model of this paper, there is a channel from a mortality decline to population growth through the social status, which is characterized by capital per person relative to the average of that in the economy. The decline in mortality stimulates investment and the more, the stronger is the desire of status, but if wealth per person grows at the same rate for all families, its marginal utility keeps constant while that of children decreases. Therefore, even though a rise in income promotes the demand for children, the families have no incentives to expand beyond the level at which their wealth

\footnotetext{
${ }^{1}$ Acemoglu and Johnson (2007) attribute the postwar mortality decline in developing countries to three factors: innovation of new drugs and chemicals, establishment of the World Health Organization, and change in international values favoring the rapid spread of new inventions. Hence, by the late 1940s, malaria was eradicated in many Asian countries (Davis 1956, Preston 1975) and mortality from infectious and tuberculosis diseases has decreased worldwide (Deaton 2003, Becker et al. 2005, Cutler et al. 2006).
} 
per person starts to decrease. The importance of status has previously been recognized by Smith (1759), who denotes the appreciation of productive assets as the "Spirit of Capitalism". Kurz (1968), Corneo and Jeanne (2001) and Fisher and Hof (2005) use status to explain economic growth only in advanced countries, but productive assets provide status in developing countries as well (Gregory 1997, Diamond 1998).

This paper attempts to explain the demographic and economic effects of the postwar mortality decline by the role of status and children in family preferences. We try to answer the following questions:

Question 1: How do status seeking and demand for children affect the patterns of capital accumulation after a mortality decline? Could a mortality decline cause capital dilution?

Question 2: How do status seeking and demand for children affect the patterns of population growth after a mortality decline? Does the population growth rate ultimately decrease below its initial level?

We construct a theoretical model and estimate its parameters from a sample of 39 developing countries in order to test its predictions. The paper is organized as follows: Section 2 constructs the family optimizing model with mortality and status-seeking. Section 3 examines the dynamics of the model and section 4 provides empirical evidence. Section 5 summarizes the results. Technical and empirical details are placed in the Appendix.

\section{The model}

\subsection{Production}

There is one good in the economy, chosen as the numeraire, and an infinitely living representative family with a fixed number $L$ of members. Each family member either rear children or work in the labor market. The population growth rate $n$ equals the fertility rate $f$ minus the mortality rate $m$ :

$$
\frac{\dot{L}}{L} \doteq \frac{1}{L} \frac{d L}{d t}=n=f-m
$$

where $t$ is time and $\left({ }^{*}\right)$ the derivative with respect to time. The number of child-rearing family members, $q f L$, is in fixed proportion $q$ to the number of 
newborns $f L$. The rest of the family, $L-q f L=(1-q f) L$, participates in the labor force. Noting this and (1), the effective labor input is given by

$$
N \doteq(1-q f) L A=[1-(n+m) q] L A,
$$

where $A$ is the exogenous productivity of labor. ${ }^{2}$ The output $Y$ of the single good is produced from labor $N$ and capital $K$ with constant returns to scale:

$$
Y=F(N, K), \quad F_{N}>0, \quad F_{K}>0, \quad F_{N N}<0, \quad F_{K K}<0, \quad F_{N K}>0,
$$

where $F$ is a linearly homogeneous function and subscripts $N$ and $K$ denote the partial derivatives with respect to $N$ and $K$, respectively.

\section{$2.2 \quad$ Preferences}

Because the stock of productive capital, $K$, is the only asset in the model, it is total wealth as well. We denote consumption by $C$, consumption per labor by $c \doteq C /(A L)$ and wealth per labor by $k \doteq K /(A L)$.

Following Razin and Ben-Zion (1975) and Becker (1991), we consider a representative family that derives utility from consumption per person, $C / L$, and the proportion of children in population $n(=$ the population growth rate). In addition, the family benefits from its status in the society. Following Lehmijoki and Palokangas $(2009,2010)$, this is proxied by its wealth per labor, $k$, over and above the average wealth per labor in the whole economy, $\kappa$. Thus, we augment the temporary utility at time $t$ by an increasing function $v(k-\kappa)$ of the status $k-\kappa$ as follows: ${ }^{3}$

$$
\begin{aligned}
& u(t)=\log (C / L)+\theta \log n(t)+\varepsilon v(k(t)-\kappa(t))= \\
& \log c(t)+\log A(t)+\theta \log n(t)+\varepsilon v(k(t)-\kappa(t)), \\
& \varepsilon>0, \quad \theta>0, \quad v^{\prime}>0, \quad v^{\prime}(0)=1,
\end{aligned}
$$

where $\theta$ and $\varepsilon$ are the constant weights for children and status. The greater $\varepsilon$ is, the greater the desire for status due to wealth. The bigger $\theta$ is, the more children the families would like to have.

\footnotetext{
${ }^{2}$ The productivity parameter $A$ is important in empirical estimation in Section 4 , but it plays no role in the theoretical analysis in this or the next Section.

${ }^{3}$ If the measure for status, $v$, were a linearly homogeneous function of $k$ and $\kappa$, we would obtain the same results with some complication.
} 
Let the constant $\rho$ be a family member's rate of time preference given that (s)he could live forever. We assume that all family members face the same mortality rate $m$. Thus, the probability of a member dying in a short time $d t$ is equal to $m d t$. In that case, $e^{-m t}$ is the probability that the family member will survive beyond the period $[0, t]$, and $e^{-m t} u(t)$ is the member's expected utility at time $t$. Noting (4), the representative family's expected utility at time $t=0$ is then given by

$$
\begin{aligned}
& U=\int_{0}^{\infty}\left(u e^{-m t}\right) e^{-\rho t} d t=\int_{0}^{\infty}[\log c+\theta \log n+\varepsilon v(k-\kappa)] e^{-(\rho+m) t} d t \\
& v^{\prime}>0, \quad v^{\prime \prime}<0, \quad v^{\prime}(0)=1, \quad \rho>0, \quad \theta>0, \quad \varepsilon>0,
\end{aligned}
$$

where $\rho+m$ is the effective discount rate in family preferences. ${ }^{4}$

\subsection{Saving}

The family uses its saving to accumulate its wealth (= capital):

$$
\dot{K} \doteq d K / d t=Y-C-\delta K, \quad \delta \in(0,1)
$$

where $\dot{K}$ is capital accumulation, $Y$ income from production, $C$ total consumption and $\delta>0$ the constant rate of capital depreciation. Noting $c \doteq C /(A L), k \doteq K /(A L),(1),(2)$ and (3), the budget constraint (6) can be expressed relative to efficient labor $A L$ as follows:

$$
\dot{k}=\frac{\dot{K}}{A L}-\frac{K}{A L} \frac{\dot{L}}{L}=F(1-(n+m) q, k)-(n+\delta) k-c .
$$

\section{Dynamics}

\subsection{The behavior of the family}

The family chooses its consumption $C$ and fertility $f$. Because there is oneto-one correspondence from $(C, f)$ to $(c, n)$ through $c \doteq C /(A L)$ and $(1)$, in the mathematical model, we can replace the former by consumption per

\footnotetext{
${ }^{4}$ Soares (2005) argues that the increase in human planning horizon is mainly due to a decrease in adult mortality, whereas a decrease in infant mortality decreases the costs of having live descendants. We do not discriminate between adult and child mortality, for simplicity.
} 
labor, $c$, and the population growth rate $n$ as the control variables of the family. The representative family maximizes its utility (5) by choosing $(c, n)$ subject to capital accumulation (7). In Appendix A, we show that this defines consumption per labor, $c$, as the following function of capital per labor, $k$, the population growth rate $n$ and the mortality rate $m$ :

$$
\begin{aligned}
& c=z(k, n, m) / \theta>0, \quad z_{k}=\left(1+q F_{N K}\right) n>0, \quad z_{m}=-n q^{2} F_{N N}>0, \\
& z_{n}>0, \quad n>0
\end{aligned}
$$

where subscripts $k, n$ and $m$ denote the partial derivatives with respect to $k$, $n$ and $m$, respectively. Because all families are similar in the model, they have the same wealth in equilibrium, $\kappa=k$. Noting this, the utility maximization of the representative family leads to the Euler equation ${ }^{5}$ (cf. Appendix A)

$$
\rho+n+m+\delta-F_{K}(1-(n+m) q, k)-\varepsilon c=-\frac{\dot{c}}{c}=-\frac{z_{k}}{z} \dot{k}-\frac{z_{n}}{z} \dot{n} .
$$

\subsection{The development of capital and population growth}

Inserting function (8) into (7), and noting (3), (9), we obtain capital accumulation $\dot{k}$ as the following function:

$$
\begin{aligned}
& \dot{k}=\vartheta(k, n, m, \theta) \doteq F(1-(n+m) q, k)-(n+\delta) k-z(k, n, m) / \theta, \\
& \left.\vartheta_{k} \doteq \frac{\partial \vartheta}{\partial k}\right|_{\dot{k}=\dot{n}=0}=F_{K}-n-\delta-\frac{z_{k}}{\theta}, \\
& \vartheta_{n}=\frac{\partial \vartheta}{\partial n}=-q F_{N}-k-\frac{z_{n}}{\theta}<0, \quad \vartheta_{m} \doteq \frac{\partial \vartheta}{\partial m}=-q F_{N}-\frac{z_{m}}{\theta}<0 .
\end{aligned}
$$

In Appendix B, noting (3), (5), (8), (10) and (9), we obtain the change in the population growth rate, $\dot{n}$, as the following function:

$$
\begin{aligned}
& \dot{n}=\varphi(k, n, m, \varepsilon, \theta), \quad \varphi_{k} \doteq \frac{\partial \varphi}{\partial k},\left.\left.\quad \varphi_{n}\right|_{\dot{k}=\dot{n}=0} \doteq \frac{\partial \varphi}{\partial n}\right|_{\dot{k}=\dot{n}=0}, \quad \varphi_{m} \doteq \frac{\partial \varphi}{\partial m} \\
& \left(\vartheta_{k}+\varphi_{k}\right)_{\dot{k}=\dot{n}=0}>0 .
\end{aligned}
$$

\footnotetext{
${ }^{5}$ Without the status effect, $\varepsilon=0$, the equation (9) would be the classical Euler equation.
} 


\subsection{Stability}

The system (10) and (11) can be linearized with respect to $(k, n, m)$ in the neighborhood of the steady state $\dot{k}=\dot{n}=0$ :

$$
\left(\begin{array}{cc}
\vartheta_{k} & \vartheta_{n} \\
\varphi_{k} & \varphi_{n}
\end{array}\right)\left(\begin{array}{c}
d k \\
d n
\end{array}\right)+\left(\begin{array}{c}
\vartheta_{m} \\
\varphi_{m}
\end{array}\right) d m=0
$$

Because the trace of this system is positive [cf. (11)], there are two solutions. First, if the Jacobian $J \doteq \vartheta_{k} \varphi_{n}-\vartheta_{n} \varphi_{k}$ is positive, then the system is globally unstable: any perturbation taking the system from the steady state forever. No economy behaves in this way. Second, if $J$ is negative, then the system has a saddle point: only one initial value of the jump variable $n$ leads to the steady state. We focus on this latter case.

In the system (10) and (11), the steady state values of the capital-labor ratio, $k^{*}$ and the population growth rate $n^{*}$ depend on the mortality rate $m$ and the preference parameters $\varepsilon$ and $\theta$. The responses of the capital stock and population growth to a mortality shock are theoretically ambiguous: ${ }^{6}$

$$
\frac{\partial k^{*}}{\partial m} \geq 0, \quad \frac{\partial n^{*}}{\partial m} \frac{\geq}{<} 0 .
$$

We sort out this ambiguity by empirical facts in the next section.

\section{Empirical evidence}

In this section, we estimate the unobservable parameters $\varepsilon$ and $\theta$ from the post-war data and regress $\partial k^{*} / \partial m \approx \Delta k / \Delta m$ and $\partial n^{*} / \partial m \approx \Delta n / \Delta m$ against the relative desire of status, $\varepsilon / \theta$, to find the empirically relevant shape of the functions (13).

On the assumption that countries follow their optimal paths and are so close to their steady states that $k=\kappa$ and $v^{\prime}(0)=1$ hold true, equations (8) and (9) can be solved for $\theta$ and $\varepsilon$ as follows:

$$
\begin{aligned}
& \theta=\left\{(f-m)\left[q F_{N}(1-q f, k)+k\right]\right\} / c \\
& \varepsilon=\left[\rho+f+\delta-F_{K}(1-q f, k)+\dot{c} / c\right] / c .
\end{aligned}
$$

\footnotetext{
${ }^{6}$ The authors will provide detailed calculations to the readers on request.
} 
As the first step to estimate $\varepsilon$ and $\theta$, note that since $1-q f$ is the labor force participation rate, one can calculate $q=(1$ - participation rate $/ f)$. The theoretical model discusses physical labor force $(1-q f) L$ alone, but for empirical purposes we apply human-capital augmented labor force (1 qf) $H$, where $H=e^{\phi(E)} L$ [cf. Hall and Jones 1999]. The function $e^{\phi(E)}$ indicates the efficiency of a worker with $E$ years of schooling $(\phi(0)=0)$, and $\phi^{\prime}(E)$ is the rate of return on schooling. We assume that this rate is constant such that each additional year increases workers' productivity by 15\% [cf. Psacharopoulos 1994]. We adopt the Cobb-Douglas formula for the production function which thus becomes:

$$
Y=F(A(1-q f) H, K)=[A(1-q f) H]^{1-\alpha} K^{\alpha}
$$

This expression indicates

$$
A=\left(Y[(1-q f) H]^{\alpha-1} K^{-\alpha}\right)^{1 /(1-\alpha)} .
$$

We assume that $\alpha=0.3$, as usually.

To calculate the country-specific values for $A$, we collected time series for $Y=G D P$, labor force participation rates, education, and investment for the 1960-2007 period from developing countries. The time series of fertility and mortality $(f$ and $m$ ) were collected in the same way. For data sources and detailed definitions of the variables, see Appendix C. The capital stocks $K$ can be calculated from investment time series by the perpetual inventory method (Caselli 2004). Thus, we are able to derive $A$ from (17) for all available years for each country. Since households in developing countries tend to be impatient, we assume $\rho=0.10$, while the assumption $\delta=0.05$ is standard. We assume that all countries share these values of $\rho$ and $\delta$.

Given the parametric expression for the production function, and the other parameters as above, we are able to calculate the preference parameters $\theta$ and $\varepsilon$ from (14) and (15) for each available year for each country. We use their average values over years as the country-specific estimates $\theta_{i}$ and $\varepsilon_{i}$ [cf. Appendix C]. The dependent variables are $\Delta k_{i}=k_{i, 2007}-k_{1,1960}$, $\Delta n_{i}=n_{i, 2007}-n_{i, 1960}$, and $\Delta m_{i}=m_{i, 2007}-m_{i, 1960}$. The sample, for which sufficient data is available, contains 39 developing countries worldwide [cf. Appendix C]. 

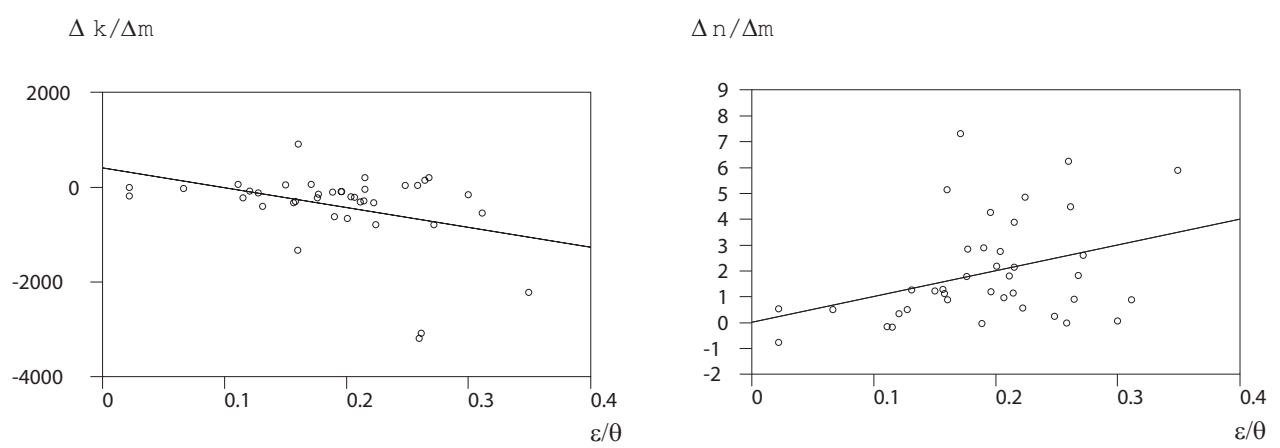

Figure 1: The response of per capita capital $k$ and population growth $n$ to change in mortality as a function of $\varepsilon / \theta$.

We are now able to regress the response functions $\partial k_{i} / \partial m_{i} \approx \Delta k_{i} / \Delta m_{i}$ and $\partial n_{i} / \partial m_{i} \approx \Delta n_{i} / \Delta m_{i}$ against the relative desire for status, $(\varepsilon / \theta)_{i}$. Figure 1 shows the observations with means -402.922 and 1.987 for $\Delta k_{i} / \Delta m_{i}$ and $\Delta n_{i} / \Delta m_{i}$, respectively. The simple linear models are:

$$
\begin{aligned}
\text { Model I }: & \Delta k_{i} / \Delta m_{i}=\gamma+\beta(\varepsilon / \theta)_{i}+\eta X_{i}+\epsilon_{i}, \\
\text { Model II }: & \Delta n_{i} / \Delta m_{i}=\zeta+\psi(\varepsilon / \theta)_{i}+\pi Z_{i}+\epsilon_{i} .
\end{aligned}
$$

In Model $I$, the covariates $X_{i}$ are the initial values for the capital stock $\left(k_{i, 1960}\right)$ and mortality $\left(\left(m_{i, 1960}\right)\right.$, both targeted to control for the cross-country variation in the starting levels. In Model II, the covariate $Z_{i}$ is the initial value for population growth $\left(n_{i, 1960}\right)$; initial mortality is not applied since it is (partially) controlled by $n_{i, 1960}$. Other covariates (e.g., government spending, taxes, trade, literacy and political stability) are problematic, as the expressions for $\theta$ and $\varepsilon$ in (14) and (15) depend on the specific formulation of the theoretical mode. To apply further covariates we should thus insert them into the theoretical model as well. We leave the development of such a model as a future challenge.

In Model I (both versions), the estimated $\beta$ is negative and significant, indicating that higher relative desire for status generates faster capital deepening. The introduction of the covariates induces a relative small change in the estimate for $\beta$. The estimated constant is not significant which, together with the negative mean for $\Delta k_{i} / \Delta m_{i}$, indicates that the predicted value for $\partial k / \partial m$ is negative for all $\varepsilon / \theta>0$. The last row shows that, depending upon the version, the relative desire for status can explain $14 \%$ or $35 \%$ of 


\begin{tabular}{|l|rr|rr||rc|rr|}
\hline \hline & \multicolumn{4}{|c||}{ Model I } & \multicolumn{4}{c|}{ Model II } \\
\hline & est. & $p$ & est. & $p$ & est. & $p$ & est. & $p$ \\
\hline constant & 415.15 & 0.244 & -1069.57 & 0.071 & 0.02 & 0.982 & -2.92 & 0.097 \\
$\varepsilon / \theta$ & -4197.33 & 0.019 & -3648.95 & 0.044 & 9.96 & 0.024 & 7.17 & 0.106 \\
$m_{1960}$ & & & 65721.36 & 0.005 & & & & \\
$k_{1960}$ & & & 101.42 & 0.083 & & & & \\
$n_{1960}$ & & & & & & & 124.120 & 0.057 \\
\hline$R^{2}$ & 0.14 & & 0.35 & & 0.13 & & 0.21 & \\
Countries & 39 & & 39 & & 39 & & 39 & \\
\hline
\end{tabular}

Table 1: The estimates and $p$-values.

the variation in the response of the capital stock. In Model II, the version without covariates gives a statistically significant positive $\psi$ so that that the decrease in population growth is the larger, the higher is the relative desire for status. The statistical importance of $\varepsilon / \theta$ is, however, eroded by the control variable $n_{1960}$ [cf. Table 1 , last column]. The estimated constant is insignificant which, together with the positive mean for $\Delta n_{i} / \Delta m_{i}$ indicates that the predicted value for $\partial n / \partial m$ is positive for all $\varepsilon / \theta>0$. We can now summarize the empirical answer to questions 1 and 2 as follows:

Proposition 1 An exogenous decline in the mortality rate $m$ increases per capita capital stock (i.e., $\partial k / \partial m<0$ for all $\varepsilon / \theta>0$ ). This increase is the larger the bigger is the relative desire for status $\left.\left(i . e ., \frac{\partial}{\partial(\varepsilon / \theta}\right) \frac{\partial k}{\partial m}<0\right)$.

Proposition 2 An exogenous decline in the mortality rate $m$ decreases the population growth rate (i.e., $\partial n / \partial m>0$ for all $\varepsilon / \theta>0$ ). This decrease is likely the greater, the bigger the relative desire for status (i.e., $\left.\left.\frac{\partial}{\partial(\varepsilon / \theta}\right) \frac{\partial n}{\partial m}>0\right)$.

\section{Conclusions}

The effect of the mortality decline on demographic and economic growth has been subject to continuous debate. The decline in mortality stimulates investment but, on the other hand, it decreases the costs of children the demand of which increases, thus tending to dilute income and capital per person. Therefore, the effect of a mortality decline on income and capital deepening is ambiguous. 
In this paper, there is a channel from a mortality decline to population growth and capital deepening through the social status from wealth. Since excessive population growth erodes wealth (capital) per person, statusseeking limits the incentives to have large families. We construct a theoretical model and estimate its parameters from a sample of 39 developing countries to show that an exogenous decline in mortality decreases the population growth rate and this decrease is likely the greater, the bigger the relative desire for status. Ultimately, population growth falls below its original level. On the other hand, per capita capital stock increases and the more, the bigger is the relative desire for status.

\section{Appendix}

\section{A Results (8) and (9)}

The family maximizes its utility (5) by choosing its growth rate $n$ and consumption per labor, $c$, subject to capital accumulation (7). The Hamiltonian of this maximization is given by

$$
\begin{aligned}
H= & \log c+\log A+\theta \log n+\epsilon v(k-\kappa) \\
& +\lambda[F(1-(n+m) q, k)-(n+\delta) k-c],
\end{aligned}
$$

where the co-state variable $\lambda$ evolves according to

$$
\begin{aligned}
& \dot{\lambda}=(\rho+m) \lambda-\partial H / \partial k \\
& =\left[\rho+n+m+\delta-F_{K}(1-(n+m) q, k)\right] \lambda-\varepsilon v^{\prime}(k-\kappa), \\
& \quad \lim _{t \rightarrow \infty} \lambda k e^{-(\rho+m) t}=0 .
\end{aligned}
$$

The maximization of the Hamiltonian (18) by the control variables $(c, n)$ for a given $\lambda$ yields the first-order conditions

$$
\frac{\partial H}{\partial c}=\frac{1}{c}-\lambda=0, \quad \frac{\partial H}{\partial n}=\frac{\theta}{n}-\left[q F_{N}(1-(n+m) q, k)+k\right] \lambda=0 .
$$

Given these two equations, (3) and (5), we can replace $\lambda$ by $n$ as the co-state variable and define consumption per labor, $c$, as a function of capital per 
labor, $k$, the population growth rate $n$ and the mortality rate $m$ as follows:

$$
\begin{aligned}
& c \doteq 1 / \lambda=z(k, n, m) / \theta>0, \quad z(k, n, m) \doteq n\left[q F_{N}(1-(n+m) q, k)+k\right], \\
& n>0, \quad z_{k} \doteq \frac{\partial z}{\partial k}=\left(1+q F_{N K}\right) n>0, \quad z_{m} \doteq \frac{\partial z}{\partial m}=-n q^{2} F_{N N}>0, \\
& z_{n} \doteq \frac{\partial z}{\partial n}=q F_{N}+k-n q^{2} F_{N N}>0 .
\end{aligned}
$$

Noting this, $\kappa=k$ and (5), we transform the equation (19) into

$$
\begin{aligned}
& \rho+n+m+\delta-F_{K}(1-(n+m) q, k)-\varepsilon c= \\
& =\rho+n+m+\delta-F_{K}(1-(n+m) q, k)-\underbrace{v^{\prime}(0)}_{=1} \frac{\varepsilon}{\lambda}=\frac{\dot{\lambda}}{\lambda}=\frac{d \log \lambda}{d t} \\
& =-\frac{d \log c}{d t}=-\frac{\dot{c}}{c}=-\frac{d \log z}{d t}=-\frac{z_{k}}{z} \dot{k}-\frac{z_{n}}{z} \dot{n}=-\frac{z_{k}}{z} \vartheta(k, n, m)-\frac{z_{n}}{z} \dot{n} .
\end{aligned}
$$

\section{B Function (11)}

Because the production function (3) is linearly homogeneous, its derivative $F_{K}(1-(n+m) q, k)$ is homogeneous of degree zero. This implies

$$
[1-(n+m) q] F_{N K}+k F_{K K}=0 \text { and } F_{K K}=-[1-(n+m) q] F_{N K} / k \text {. }
$$

Rearranging terms in (9) and noting (3), (5), (8), (10) and (20), we obtain

$$
\begin{aligned}
& \dot{n}=\varphi(k, n, m, \varepsilon, \theta)={ }^{(9)} \\
& \frac{z}{z_{n}}\left[F_{K}(1-(n+m) q, k)+\frac{\varepsilon}{\theta} z(k, n, m)-n-m-\delta-\rho\right]-\frac{z_{k}}{z_{n}} \dot{k}= \\
& \frac{z}{z_{n}}\left[F_{K}(1-(n+m) q, k)+\frac{\varepsilon}{\theta} z(k, n, m)-n-m-\delta-\rho\right]-\frac{z_{k}}{z_{n}} \vartheta(k, n, m, \theta),
\end{aligned}
$$

with

$$
\begin{aligned}
\left.\varphi_{k}\right|_{\dot{k}=\dot{n}=0} & =\left.\frac{\partial \varphi}{\partial k}\right|_{\dot{k}=\dot{n}=0}=\frac{z}{z_{n}}\left(\frac{\varepsilon}{\theta} z_{k}+F_{K K}\right)-\underbrace{\frac{z_{k}}{z_{n}}} \underbrace{\left.\vartheta_{k}\right|_{\dot{k}=\dot{n}=0}}_{-}, \\
\left.\varphi_{n}\right|_{\dot{k}=\dot{n}=0} & =\left.\frac{\partial \varphi}{\partial n}\right|_{\dot{k}=\dot{n}=0}=\frac{z}{z_{n}}\left(\frac{\varepsilon}{\theta} z_{n}-1-q F_{N K}\right)^{+}-\frac{z_{k}}{z_{n}} \vartheta_{n} \\
& ={ }^{(10)} \frac{z}{z_{n}}\left(\frac{\varepsilon}{\theta} z_{n}-1-q F_{N K}\right)+\frac{z_{k}}{z_{n}}\left(q F_{N}+k+\frac{z_{n}}{\theta}\right) \\
& \left.={ }^{(8)} \frac{\varepsilon}{\theta} z+\frac{1}{z_{n}}[\underbrace{\left(q F_{N}+k\right.}_{=z / n}) z_{k}-(\underbrace{1+q F_{N K}}_{=z_{k} / n}) z\right]+\frac{z_{k}}{\theta}=\frac{\varepsilon}{\theta} z+\frac{z_{k}}{\theta}>0,
\end{aligned}
$$




$$
\left.\varphi_{m}\right|_{\dot{k}=\dot{n}=0}=\left.\frac{\partial \varphi}{\partial m}\right|_{\dot{k}=\dot{n}=0}=\frac{z}{z_{n}}\left(\frac{\varepsilon}{\theta} z_{m}-1-q F_{N K}\right)-\underbrace{\frac{z_{k}}{z_{n}}}_{+} \underbrace{\vartheta_{m}}_{-} .
$$

From this it follows that

$$
\left(\vartheta_{k}+\varphi_{n}\right)_{\dot{k}=\dot{n}=0}=\underbrace{\left(F_{K}-n-\delta\right)_{\dot{k}=\dot{n}=0}}_{=\rho+m-z \varepsilon / \theta}-\frac{z_{k}}{\theta}+\frac{\varepsilon}{\theta} z+\frac{z_{k}}{\theta}=\rho+m>0 .
$$




\section{Estimated Parameters and Data}

\begin{tabular}{|c|c|c|c|c|c|}
\hline Country & $\theta$ & $\varepsilon$ & $\varepsilon / \theta$ & $\Delta k / \Delta m$ & $\Delta n / \Delta m$ \\
\hline Algeria & 1.516 & 0.313 & 0.207 & -208.2521739 & 0.962 \\
\hline Argentina & 0.324 & 0.085 & 0.261 & -3077.713636 & 4.482 \\
\hline Benin & 0.258 & 0.006 & 0.022 & -4.561832524 & -0.762 \\
\hline Bolivia & 0.241 & 0.060 & 0.248 & 30.4148732 & 0.263 \\
\hline Brazil & 0.341 & 0.069 & 0.204 & -200.7156805 & 2.751 \\
\hline Central African Republic & 0.134 & 0.015 & 0.111 & 59.12245431 & -0.137 \\
\hline Chile & 0.481 & 0.103 & 0.215 & 208.0119015 & 2.131 \\
\hline Colombia & 0.334 & 0.059 & 0.177 & -138.7519757 & 2.842 \\
\hline Costa Rica & 0.414 & 0.079 & 0.190 & -615.2168869 & 2.902 \\
\hline Dominican Republic & 0.387 & 0.068 & 0.176 & -219.7983623 & 1.785 \\
\hline Ecuador & 0.498 & 0.098 & 0.196 & -89.90767018 & 1.194 \\
\hline El Salvador & 0.300 & 0.063 & 0.211 & -305.0615385 & 1.809 \\
\hline Fiji & 0.436 & 0.098 & 0.224 & -789.119685 & 4.858 \\
\hline Ghana & 0.160 & 0.026 & 0.161 & 913.9719463 & 0.893 \\
\hline Guatemala & 0.489 & 0.092 & 0.189 & -105.0980303 & -0.035 \\
\hline Honduras & 0.485 & 0.108 & 0.222 & -327.3872948 & 0.558 \\
\hline India & 0.388 & 0.050 & 0.128 & -112.8783396 & 0.503 \\
\hline Indonesia & 0.335 & 0.007 & 0.022 & -180.9121415 & 0.528 \\
\hline Iran & 1.002 & 0.159 & 0.158 & -299.8465187 & 1.124 \\
\hline Jamaica & 0.363 & 0.094 & 0.260 & -3179.43887 & 6.252 \\
\hline Kenya & 0.142 & 0.009 & 0.067 & -32.61138311 & 0.525 \\
\hline Malawi & 0.138 & 0.036 & 0.258 & 35.19255639 & -0.001 \\
\hline Malaysia & 0.489 & 0.064 & 0.131 & -404.3307312 & 1.276 \\
\hline Mauritius & 0.246 & 0.042 & 0.171 & 60.92090909 & 7.318 \\
\hline Mexico & 0.442 & 0.089 & 0.201 & -654.504908 & 2.190 \\
\hline Nicaragua & 0.588 & 0.183 & 0.311 & -543.1936282 & 0.892 \\
\hline Pakistan & 0.505 & 0.061 & 0.121 & -78.71442901 & 0.341 \\
\hline Panama & 0.449 & 0.122 & 0.272 & -791.4231203 & 2.613 \\
\hline Papua New Guinea & 0.372 & 0.043 & 0.115 & -217.7042098 & -0.169 \\
\hline Paraguay & 0.237 & 0.038 & 0.160 & -1323.858175 & 5.144 \\
\hline Peru & 0.342 & 0.090 & 0.264 & 158.6609531 & 0.908 \\
\hline Philippines & 0.271 & 0.058 & 0.214 & -284.1538547 & 1.150 \\
\hline Sri Lanka & 0.326 & 0.064 & 0.196 & -96.61818182 & 4.258 \\
\hline Thailand & 0.201 & 0.070 & 0.349 & -2218.450363 & 5.891 \\
\hline Togo & 0.321 & 0.096 & 0.300 & -162.8579278 & 0.071 \\
\hline Tunisia & 0.542 & 0.081 & 0.150 & 53.88922156 & 1.214 \\
\hline Turkey & 0.465 & 0.073 & 0.157 & -328.6466837 & 1.284 \\
\hline Venezuela & 0.956 & 0.206 & 0.215 & -43.01564482 & 3.890 \\
\hline Zambia & 0.328 & 0.088 & 0.268 & 203.5090426 & 1.824 \\
\hline
\end{tabular}




\begin{tabular}{lrrrrr}
\hline \hline Country & $\theta$ & $\varepsilon$ & $\varepsilon / \theta$ & $\Delta k / \Delta m$ & $\Delta n / \Delta m$ \\
\hline Togo & 0.321 & 0.096 & 0.300 & -162.8579278 & 0.071 \\
Tunisia & 0.542 & 0.081 & 0.150 & 53.88922156 & 1.214 \\
Turkey & 0.465 & 0.073 & 0.157 & -328.6466837 & 1.284 \\
Venezuela & 0.956 & 0.206 & 0.215 & -43.01564482 & 3.890 \\
Zambia & 0.328 & 0.088 & 0.268 & 203.5090426 & 1.824 \\
\hline
\end{tabular}

The variables, their sources, and the maximal data availability are:

$G D P=$ real gross domestic product, base year 2005, Laspayres index. Source: Heston et al. (2009), 1960-2007, all years.

Investment $=$ proportion of investment in GDP. Source: Heston et al. (2009), 1960-2007, all years.

Fertility $f=$ crude birth rate, number of births per hundred people. Source: World Bank (2009), 1960-2007, some years missing.

Mortality $m=$ crude death rate, number of deaths per hundred people. Source: World Bank (2009), 1960-2007, some years missing.

Population growth $n=f-m$. Source: World Bank (2009). 1960-2007, some years missing.

Participation rate $=$ Total labor force participation rate. Source: World Bank (2009), 1980-2007. To avoid the loss of years, the average over available years is applied for 1960-2007.

Schooling = average years of schooling, both sexes. Source: Barro and Lee (2000), 1960-2000. The quinquennially available data is imputed such that the intermediate years take the values of the earlier years.

$\theta_{i}$ : estimated as a country-specific average over all available years from 1960 to 2007 .

$\varepsilon_{i}$ : estimated as a country-specific average over all available years from 1960 to 2007.

The sample initially contained 56 developing countries, but due to small capital stocks in some countries, the marginal product of capital $\left(F_{2}\right)$ is so large that the calculated $\varepsilon$ fails to satisfy the constraint $\varepsilon>0$, thus limiting the sample to 40 countries. Of these, South-Africa turns out to to be an outlier, exhibiting excessive values for $\Delta n / \Delta m$ due to its very small decrease in mortality. Thus the final sample contains 39 countries. 


\section{References:}

Acemoglu, Daron and Johnson, Simon (2007): Disease and Development: The Effect of Life Expectancy on Economic Growth. Journal of Political Economy 115, 925-985.

Albanesi, Stefania and Olivetti, Claudia (2010): Maternal Health and the Baby Boom. Centre for Economic Policy Research (CEPR), Discussion Paper No. DP7925.

Barro, Robert J. and Jong-Wha Lee (2000): International Data on Educational Attainment: Updates and Implications. CID Working Paper No. 42.

Becker Gary S. (1991): A Treatise on the Family. Enlarged Edition, Harvard University Press, Cambridge.

Becker, Gary S., Philipson, Tomas J. and Soares, Rodrigo R. (2005): The Quantity and Quality of Life and the Evolution of World Inequality. American Economic Review 95(1), 277-291.

Blackburn, Keith and Cipriani, Giam P. (2002): A Model of Longevity, Fertility and Growth. Journal of Economic Dynamics \& Control 26, 187-204.

Caselli, Francesco (2004): Accounting for cross-country income differences. CEPR Discussion Paper 4703.

Corneo, Giacomo and Jeanne, Oliver (2001): On Relative-Wealth Effects and Long-Run Growth. Research in Economics 55(4), 349-358.

Cutler, David, Deaton, Angus, and Lleras-Muney, Adriana (2006): The Determinants of Mortality. Journal of Economic Perspectives 20(3), 97-120. Davis, Kingsley (1956): The Amazing Decline of Mortality In Underdeveloped Areas. American Economic Review, Paper and Proceedings 46(May), 305-318.

Deaton, Angus (2003): Health, Inequality, and Economic Development. Journal of Economic Literature 41(1), 113-158.

Diamond, Jared (1998): Guns, Germs, and Steel: The Fates of Human Societies. Vintage, London.

Doepke, Matthias (2005): Child Mortality and Fertility Decline: Does the Barro-Becker Model Fit the Facts? Journal of Population Economics 18, 337-366.

Ehrlich, Isaac and Kim, Jinyoung (2005): Endogenous Fertility, Mortality, and Economic Growth: Can a Malthusian Framework Account for the Conflicting Historical Trends in Population? Journal of Asian Economics 16(5), 789-806.

Fisher, Walter H. and Hof, Franz X. (2005): Status Seeking in a Small Open Economy. Journal of Macroeconomics 27(2), 209-232.

Galor, Oded and Weil, David (2000): Population, Technology, and Growth: from Malthusian Stagnation to the Demographic Transition and Beyond. American Economic Review 90, 806-826. 
Gregory, Chris (1997): Savage Money: Anthropology and Politics of Commodity Exchange. Harwood Academic Publishers, Amsterdam.

Hall, Robert and Jones, Charles (1999): Why do some countries produce so much more output per worker than others? Quarterly Journal of Economics $114,83-116$.

Heston, Alan, Summers, Robert and Aten, Bettina (2009): Penn World Table Version 6.3, Center for International Comparisons at the University of Pensylvania (CICUP). U.S.A.

Kurz, Mordecai (1968): Optimal Economic Growth and Wealth Effects. International Economic Review 9(3), 348-357.

Lehmijoki, Ulla and Palokangas, Tapio (2009): Population Growth Overshooting and Trade in Developing Countries. Journal of Population Economics 22, 43-56.

Lehmijoki, Ulla and Palokangas, Tapio (2010): Trade, Status, Population growth, and the Environment in Developing Countries. Journal of Population Economics 23, 1351-1370.

Malthus, Thomas R. (1798): An Essay on the Principle of Population, as it Affects the Future Improvement of Society with Remarks on the Speculations of Mr. Godwin, M. Condorcet, and Other Writers, London, Printed For J. Johnson, In St. Paul's Church-Yard.

Psacharopoulos, George (1994): Returns to Investment in Education: A Global Update. World Development 22(9), 1325-1343.

Preston, Samuel H. (1975): The Changing Relation Between Mortality and Level of Economic Development. Population Studies 29(2), 231-248.

Razin, Assaf and Ben-Zion, Uriel (1975): An Intergenerational Model of Population Growth. American Economic Review 65, 923-933.

Smith, Adam (1759): The Theory of Moral Sentiments. Reprint, Liberty Fund, Indianapolis 1982.

Soares, Rodrigo R. (2005): Mortality Reductions, Educational Attainment, and Fertility Choice. American Economic Review 95(3), 780-795.

Zhang, Jie and Zhang, Junsen (2005): The Effect of Life Expectancy on Fertility, Saving, Schooling and Economic Growth: Theory and Evidence. Scandinavian Journal of Economics 107(1), 45-66.

Weil, David N. (2007): Accounting for the Effect of Health on Growth. Quarterly Journal of Economics 122(3), 1265-1306.

World Bank (2009): World Development Indicators 2009 On-line version. Oxford University Press, New York.

Young, Alwyn (2005): The Gift of the Dying: The Tragedy of AIDS and the Welfare of Future African Generations. Quarterly Journal of Economics CXX(2), 423-466. 